\title{
Addressing Pedagogical Usability and Mobility Barriers in E-learning Systems: A Case of Youth Entrepreneurship Skill Development, Plan International Uganda
}

\author{
Tamale Med, Andrew Lukyamuzi \\ Faculty of Science, Uganda Martyrs University, Kampala, Uganda \\ Email address: \\ medtamale $a$ gmail.com (T. Med), AndrewLukyamuzi $a$ gmail.com (A. Lukyamuzi) \\ To cite this article: \\ Tamale Med, Andrew Lukyamuzi. Addressing Pedagogical Usability and Mobility Barriers in E-learning Systems: A Case of Youth \\ Entrepreneurship Skill Development, Plan International Uganda. International Journal of Sustainable Development Research. \\ Vol. 5, No. 3, 2019, pp. 56-70. doi: 10.11648/j.ijsdr.20190503.11
}

Received: January 23, 2019; Accepted: March 13, 2019; Published: October 23, 2019

\begin{abstract}
Adoption of E-learning systems to address youth self-reliance entrepreneurship skills knowledge gap in developed countries has been rapidly evolving and reached advanced stages. Nonetheless, in the developing world most especially SubSahara Africa it is still infancy. Of recent, some Non-Governmental Organizations have attempted implementation of Elearning systems as alternative means to traditional elitist spaces to equip the youth with self-reliance job start-up skills. However, despite the usual challenge of ICT infrastructure development, pedagogical usability and accessibility concerns are key undermining barriers to this initiative. This study therefor focuses on design and implementation of a youth entrepreneurship skills E-learning system prototype, ported on mobile technology with an integrated informal lifelong learning model. The proposed infrastructure also accommodates a mobile learning tool that enhances access and usability concerns of out-of-school youth lifelong learners in developing countries like Uganda. System design and development was achieved through a user centred participatory design approach (UCD) in conjunction with Human access point (HAP) design technique. User requirements inform of low-fidelity card paper prototypes were later transformed into working system interfaces. The developed prototype with both web and native mobile tool simplifies the process of self-employment business start-up skills access and development using interactive videos. Similarly, the system guides a youth in selection of appropriate survival skills, and selection of the learning path based on one's previous experience. In addition, the learning environment helps the youth to connect with skilled experts and coaches experienced in vast areas of the business. Conclusively, the platform helps survival skills providers to reach the unreached youth and monitoring of active youth ongoing projects. Evaluation of the developed system prototype was streamlined on the Unified Theory of Technology and Acceptance Model (UTAUT). From here user's feedbacks on the developed prototype were gathered using Survey questionnaires. Study findings revealed that mobile technology can bridge youth survival entrepreneurship skills knowledge gap in developing countries. Similarly, youth survival skills provider's responses on the developed prototype in terms of system access and usability were positive. Briefly, study findings revealed that personalized Smart mobile learning system architecture bridges pedagogical usability and mobility barriers in youth entrepreneurship skills development E-learning systems implementation in developing countries like Uganda.
\end{abstract}

Keywords: Personalized Mobile Learning, Self-Determined Learning, Smart Lifelong Learning, Lifelong Mobile Learning for Youth, User Centered Design, Human Access Point (HAP), Technology and Acceptance Models

\section{Introduction}

Currently, youth unemployment has been pointed out as one of the most challenging phenomenon in developing countries [1]. The working youth population in the region is expected to increase from 370 million to 600 million by 2030 [2]. Uganda is among developing countries striving with the same challenge whereby 64-70 per cent of the youth in the 
economy are unemployed [3]. Though Uganda's economy registers around 600,000 to 700,000 new youth job seekers in the labour market each year, only 9000 youth can manage to secure employment through hustle. Meanwhile, cases of human trafficking in the Middle East and anti-social rebel actions among youth groups in states like Nigeria have been witnessed as negative impacts of youth unemployment on Africa continent [4, 5]. Similarly, anti-social malpractices such as gambling, insecurity, and cybercrime in Uganda's economy have been observed as impacts of youth unemployment [6, 7]. In addition, formulation of youth jobless brotherhood groups in Uganda's economy has been aligned on the theme "The Alarming Youth Unemployment in the economy". Although causes of youth unemployment vary from state to state and region to region, financial crisis, Skills mismatch, Lack of entrepreneurship and life skills education, digital divided gap, and Lack of access to capital are among the major causes of youth unemployment in Africa [8]. Scaling it back to Uganda's context, factors such as; Nepotism, corruption, lack of access to information about labour markets, limited education or skills, and lack of entrepreneurship and management skills are root causes of youth unemployment in the economy [9]. The education system itself has continuously failed to equip the youth with constructive self-reliance employability skills rather than focusing more on filling the demands of the business sectors.

In the previous years, there has been increasing commitment of the government and Non-Governmental Organisation in Uganda to curb the problem of youth unemployment and some of the strategic measures spearheaded by the government include; provision of youth livelihood fund, youth venture capital fund access through commercial banks, formulation of Youth SACCOs, and bringing on board Business technical and vocational programs (BTVET) [10]. On the other hand NonGovernmental organisations such as Plan international Uganda have responded on the same mission with provision of youth self-reliance entrepreneurship skills training programs offered through traditional elitist spaces. In addition, other stakeholders like Vodafone Uganda have embarked on implementation of the E-learning platforms to empower unemployed youth in Uganda's economy with employability skills development from different working context. Although all the above mentioned measures have been given much consideration and put into practice, youth unemployment in Uganda's economy is still ticking as a time bomb. According to study done by UNFPA, there is still need for further exploration of actions to curb youth unemployment challenge in Uganda's economy [46].

The undermining barriers to youth survival entrepreneurship skills development initiatives in Uganda's economy are but not limited to the following; (1) Inadequate skills access, (2) lack of career guidance communication mechanism between youth communities, and the youth are not aware of these Skilling Programs [11]. Additionally, tracking the progress of youth participants is also more challenging [12]. Scholarly work from Pletscher, also clarified that while unemployed youth in Uganda's economy possesses entrepreneurship spirit, but the capability and skills desired to become successful entrepreneurs are still lacking [13]. Still, higher discontinuity, business closure among youth-led businesses in Uganda's economy has been held back by the entrepreneurship knowledge gap [14].

From the research view perspective, while application of E-learning system presents exciting opportunities to bridge the above mentioned barriers, and promising research studies have been reported in the literature to achieve the same mission [15-24]. Nevertheless, E-learning systems themselves have their own implementation barriers such as: poor ICT infrastructure [25], User technicalities and system usability concerns [26-27], and lack of a systematic approach to guide implementation of E-learning systems in developing countries like Uganda [29]. Therefore, direct application of E-learning systems in delivering out of school youth sustainable education without addressing reported ground barriers will be just attracting additional challenges. Other open identified barriers included; reported systems mostly being computer access based, and systems being designed for youth trainers.

This study therefore proposed an E-learning system on a mobile technology to bridge youth sustainable skills access and pedagogical usability challenges through an integrated informal lifelong learning model, designed based on a user centred participatory design approach. The proposed integrated informal mobile lifelong learning model was designed through integration of a smart lifelong learning architecture as suggested in [30] work, together with design principles of a self-determined learning framework ported on a mobile infrastructure to ease youth survival skills access.

In other words, empowering youth with sustainable skills development and access through a mobile infrastructure is more likely to be achieved in Africa due to increased penetration of mobile devices by the youth [31]. This is evident because South Africa has the highest number of smartphone subscribers in Africa with 34 percentage rate followed by Nigeria, Senegal and Kenya yet Ugandan's, Ghanaian's and Kenyan's download game apps on their smartphones more than any other application a day. This study focuses on implementation of a personalised mobile learning system tool prototype not a fully working system that can bridge out of school youth entrepreneurship skills knowledge gap in Uganda's economy by encouraging them become job creators through a community of practice mobile learning environment.

\subsection{Statement of the Problem}

Africa has one of the largest numbers of unemployed youth in the world with Sub-Sahara Africa almost representing 70 percent [34]. Uganda is among African countries challenged by the same phenomenon where around $600,000-700,000$ new youth job seekers are in the labor market each year to compete for 9000 available jobs [3]. Although measures such as youth self-employment skills development programs offered through traditional elitist 
spaces and E-learning initiatives have been observed as some of the recent actions to curb the challenges, these have been hindered by; inadequate skills access, lack of career guidance communication mechanisms for youth communities, and the youth are not aware of these Skilling Programs [11]. In addition, tracking youth participants and locating them is also more challenging [12]. Similarly, while current E-learning systems offers learning enhancements such as collaboration, sharing and self-paced learning, but do not adequately provide solution to the demands of youth lifelong learners for sustainable development. The stumbling blocks in e-learning for youth skills development include: (1) Usability issues as observed in open source learning management systems such as Moodle [26, 27]; (2) limited accessibility mainly due to poor ICT infrastructure and inadequate computer resources [25]; and (3) limited opportunities for student centered learning [28].

The growing number of mobile technology can offer unique opportunities to address accessibility challenges. Therefore, this study proposes a mobile based e-learning system tool to promote increased accessibility and usability through integrated informal mobile lifelong learning systems architecture. From here a user (Youth) centered system design approach was adopted during the system development process to enhance usability. And interactive videos were used to boost youth learning engagement and performance during employability skills development process.

\subsection{Objectives of the Study}

\subsubsection{Main Objective}

The main objective of the study was to investigate how a personalized mobile learning system tool can address pedagogical usability and accessibility barriers in youth entrepreneurship skills development E-learning systems implementation in Non-governmental organizations.

\subsubsection{Specific Objectives}

I. To study the current youth learning system at Plan international Uganda and review of related literature on youth sustainable skill development E-learning systems.

II. To design a personalized mobile learning (PML) system architecture that addresses pedagogical usability and accessibility barriers in E-learning systems for youth sustainable skills development.

III. To implement a PML system that enables the working feature departments of plan international Uganda reach the unreached youth in the economy at a least cost effective and efficient learning approach.

IV.To validate and evaluate the usefulness of a Personalized mobile learning system tool by the stakeholders.

\subsubsection{Research Contribution}

This study presents numerous contributions from different angles. Besides personalization of youth self-employment survival skills access on a mobile infrastructure powered by an underlining informal out of school youth lifelong learning architecture, the system automatically fosters youth survival skills access that best suits ones proposed skills development plan, based on one's previous experience and skills masterly level.

Compared to other reported video learning environments, our prototype speeds up the process of skills development using interactive videos and from here a youth is being given an opportunity to select his/her learning path.

Despite the fact that our prototype is easy to use and can accommodate every youth participant from different academic background, it uniquely accommodates a youth project monitoring or tracking component that is in position to manage and monitor youth active ongoing projects instantly which is a missing feature from all reported platforms.

\section{Literature Review}

\subsection{Personalized Mobile Learning}

Personalized learning involves customization of learning resources and putting the learner almost in charge of the learning process $[35,51]$. Technology enabled personalized learning enhances customization of the learning process according to learners' passion, interest, and topics that are meaningful and relevant to him to develop knowledge and skills required to succeed [47]. This learning approach speeds up the process of skills development because learning emphasis is strategically aligned on key interesting areas of the study [48]. From here learning resources can easily be accessed using handheld devices such as mobile devices [49]. According to study done by Bartle, personalized learning process is driven by three major elements namely; locus of control where a student in control of the learning process, collaboration, and the instructor is well versed with the students' study areas of interest [36].

\subsection{Lifelong Mobile Learning for Youth Skills Development}

Lifelong mobile learning for skills development (LmL4SD) is quite a new study domain in ICT for youth workforce development [38]. This skills development approach enhances development of employability skills required by the youth and acquisition of new business startup ideas with the help of mobile technologies. It should be noted that lifelong learning for skills development is a sub set of non-formal learning that can be conducted outside classroom environment. However, formal learning approaches such as assessment can be used to measure student's skills mastery level of the course content.

\subsection{Smart Lifelong Learning Environment}

Study done by Magoulas, defines a smart lifelong learning environment as a learning approach designed on the theme "helping a learner in selection of appropriate lifelong learning resources or experience based on myriad of learning 
resources surrounding him or her" [30]. Magoulas further states that, a smart lifelong learning environment has the capability to address learning barriers in traditional learning approaches such as; pedagogy, andragogy and heutagogy (PAH). In otherwards, a typical smart lifelong learning environment consists of nine elements including; Enterprise service bus, Learning management system, E-Portfolio tool, Social media, learning records Store, Media Space, Webbased Intelligent Education system, and Learning Design Tools.

\subsection{Self-Determined Learning Approach}

Current education systems have been posed to challenges of developing lifelong learners who are capable of thriving in the global challenging world [39]. This has been aligned on design constraints in traditional learning approaches which have been modeled to fill requirements and demands of business sectors. However, a self-determined learning approach has come to address instruction design challenges in traditional learning approaches. Meanwhile a selfdetermined learning approach enhances development of capable and flexible learners who can dynamically respond to complex and challenging situations within the twenty first century world [40]. Briefly heautogogy is a student centered learning approach that emphasizes development of life-long learning skills in preparation for uncertain world [41]. The learning process is basically structured on non-linear design where the learners determine their learning path rather than the tutor and the design principles underpinning a selfdetermined learning environment entails; exploration, creation, collaboration, sharing, connection and reflection [53].

\subsection{Related Studies}

Limited studies have been carried out on mobile technologies for youth work force development in which researchers presented opportunities and drawbacks of each approach. Study done Mohd, reported a Massive Open Online Courses (MOOC) virtual learning initiative implemented to embrace the impact of ICT and digitalization of education system in solving youth unemployment and lifelong learning challenges in European countries [15]. The platform helps both in and out of school youth access survival skills on computers and mobile devices and learning resources are presented in form of text, audios, and videos. Although the platform presents learning resources superbly, implementation of such platform in the developing world require significant amount of money, skills, energy and resources. In addition, absence of serious pedagogy in MOOCs also scares potential adopters of the platforms [42].

Another ICT development initiative for youth work force development through entrepreneurship has been reported from Anderson, work [16]. A community based E-commerce web portal (Taobao.com) which helps individual sellers and buyers most especially the youth with previously unavailable avenue for participating in Entrepreneurship activities. The platform specifically helps the youth to launch entrepreneurship ventures. In facts round 65 million chines' individuals and 12 enterprises in the economy have opened electronic shops on this platform. Of recent International Labour Organization has launched "Start and improve your business" entrepreneurship training platform for the youth most especially the females [17]. The platform helps the youth to develop entrepreneurship skills, start and improve on their own business knowledge, access markets, and value chain development. But the platform uses a train-the-trainer strategy where around 200 master trainers globally train other trainers from different partner organizations around the world. Another ICT innovation to bridge the digital divide knowledge gap among youth has been reported from India economy. An online national web based skills learning environment has been put in place to equip job aspirants, onthe-job trainees and students with soft digital literacy skills using audio-video graphical illustrations and nugget resources. From here learning resources can be accessed on computers or mobile devices.

In 2014 the Communication and Information Sector of United Nations Educational, Scientific and Cultural Organization (UNESCO) launched youth mobile initiative which was specifically formulated to help large groups of youth globally develop technical skills in mobile application development, and Entrepreneurship skills as a source of employment to unemployed youth [19]. UNESCO cooperated with its member states worldwide and they designed a formal mobile application development curriculum where a master trainer teaches the teachers, and the teachers therefore teach the students. Training takes place through seminars and workshops which are scheduled in convenient periods.

Ogunleye scholarly work, also presents a web based center for entrepreneurship development, and skills development (CADESA) platform at University of Legos Nigeria implemented on theme "creation of an entrepreneurial society platform for equipping community member's especially youth with self-employment skills for sustainable growth" [20]. The web based E-skills development platform helps youth to develop wide range of skills. Similarly, project NAMCOL also involved implementation of the national community literacy program for out-of-school youth and adult lifelong learning for self-employment in Namibia [21]. The E-learning platform was integrated within Namibia College of open learning initiative for human capacity development using Moodle and Notes master learning management systems. Although electronic content developers most especially in developing countries prefers harnessing opportunities of open source learning management systems to carry out their initiatives, but research done by Almarabeh and Kasse, clarifies that students encounters several challenges while working on open source learning management platforms such as Moodle in developing countries [26, 27].

Project done by Nygren, also presents a hybrid mobile system for youth coaches running on android, iOS and web service to improve on youth coaches abilities to learn and 
teach entrepreneurship skills desired by disadvantaged youth in different parts of Uganda and Zambia [23]. However, it should be noted that the application was designed specifically for youth coaches not the youth. Of recent, Vodafone launched Jump project in Uganda that resulted into implementation of a web based E-learning Platform to Provide Ugandan Youth with free access to selfreliance entrepreneurship skills. The platform helps the youth develop soft skills in areas of Education, Entrepreneurship, Self-improvement, and Lifestyle improvement. Otherwise the main objective of the initiative was to implement an interactive E-library learning environment where the youth, and upcoming entrepreneur can be empowered with various skills development of interest. The platform provides online learning materials to students with numerous study notes and a series of video lectures from Ugandan lecturers [24].

After careful review of the literature, it can be concluded that E-learning fosters distance learning for youth sustainable skills development, makes enormous advances in the quality of teaching, and can offers flexible learning opportunities for youth sustainable employability skills development globally. In the reported literature there was no single common communication mode from the scholars, institutions and individuals developing E-learning systems for youth sustainable skills development besides emphasizing Entrepreneurship and Vocational resource digital packaging. It can be concluded that the common identified barrier to Elearning success for youth workforce skills development in developing countries entails;

i. Most of the reported ICT innovations in developing countries have been streamlined on implementation of web-based youth survival skills development platforms. However, due to human technology adoption constraints such as; poor ICT infrastructure and financial abilities of the youth from developing countries who cannot even purchase computer resources; it becomes harder for them to fully harness reported innovations [50]. Therefore, there is still need to tap recent advancements in mobile technologies as a solution to the above mentioned barriers to boost youth workforce skills development program [32].

ii. Absence of pedagogy in reported platforms has raised out concerns such as limited opportunities for student centered learning, and there's still need for further research directions to address systems usability, pedagogical usability concerns, cultural issues in design and development of web based learning environments in Sub-Sahara countries [33].

Other open identified barriers included; systems being designed for youth trainers only, while under looking the youth themselves. In this paper we presented personalized mobile learning system architecture, with both web and a mobile learning tool that can be used by disadvantaged youth to develop or access self-reliance business start-up skills in Uganda's economy.

\section{Research Methodology}

Our thesis adopted a user centered research design approach. According to Rauterberg, a user centered design approach advocates for involving system users throughout the design process of the system development so as to create highly usable and accessible software's [52].

The research method used in data collection and analysis consisted of mixed research methods where an exploratory research strategy was used to clearly understand the research phenomenon. Actually, a sequential exploratory mixed methodology was adopted to increase generalizability of study findings [43]. Quantitative data was gathered using survey questionnaires, and qualitative data was gathered using interviews, focus group discussions and observation.

Similarly, a Human Access Point Design technique (HAP) was utilized on different stages of system development. This system development methodology clarifies taking into account or involving system user's needs in understanding developments, expertise's and performance while designing a system [44].

\subsection{Population and Samples}

The study was conducted at plan international Uganda headquarters in Uganda East Africa which is a nongovernmental organization. However, it should be noted that the sample population selection process involved selection of a particular group of disadvantaged youth impacted by plan international youth economic empowerment program, and non-impacted group of youth from Kampala and Mpigi district. This was done that way, to streamline balance in our study findings.

From here a purposive sampling technique was used where 120 youth where selected to be part of the sample population, 6 youth trainers, 3 project managers and 1 IT officer. In other words the sample size was computed based on the finite population correlation factor methodology together with the Yamane, sample size computation formulae [56].

\subsection{Data Analysis and Methods}

Qualitative data and quantitative responses were gathered based on interviews, questionnaires, focus group discussions and observation instruments from the youth coaches, skilled experts, and the youth. However, qualitative and quantitative data was gathered from 120 youth, 6 youth trainers, 3 project managers and 1 IT officer. Survey questionnaire were used as main quantitative data collection instruments, and quantitative data was processed by descriptive statistics using SPSS 16.0.

Examples of the Qualitative data collection methods included observation, interviews, and focus groups. Analysis of qualitative data was streamlined on four (4) interview instruments sub themes including; respondent's details (bio demography), current training approach, and challenges of existing system with respondent's perceptions on the proposed system sub sections. 
On the other hand quantitative survey questionnaires which were used to gather user's feedbacks on the developed prototype were analyzed based on the Unified Theory of Technology and Acceptance Model predictive variables including, Effort Expectancy, Performance expectance, Facilitating condition, and Social influence elements.

\section{Personalized Mobile Learning System Tool (PMLST) Design}

Initial development phase of the system involved gathering of youth requirements inform of low-fidelity card paper prototypes. From here, iterative design sessions administered by the researcher through Focus Group Discussions resulted into development of low-fidelity paper prototypes. This was followed by low-fidelity paper prototype refinement phase where unstructured interfaces design errors, and corrections were made. And this led to transformation of low-fidelity card prototypes into high-fidelity prototypes (working interfaces).

However, it should be noted that, before design sessions youth co-design team 1 and 2 (10) that consisted of five members in each group were introduced to web and mobile paper mockups design concepts to ideally bring their attentions and focus before real PMLS tool interfaces design sessions. Figure 1 below shows sample low-fidelity paper prototypes produced by the youth co-design team.

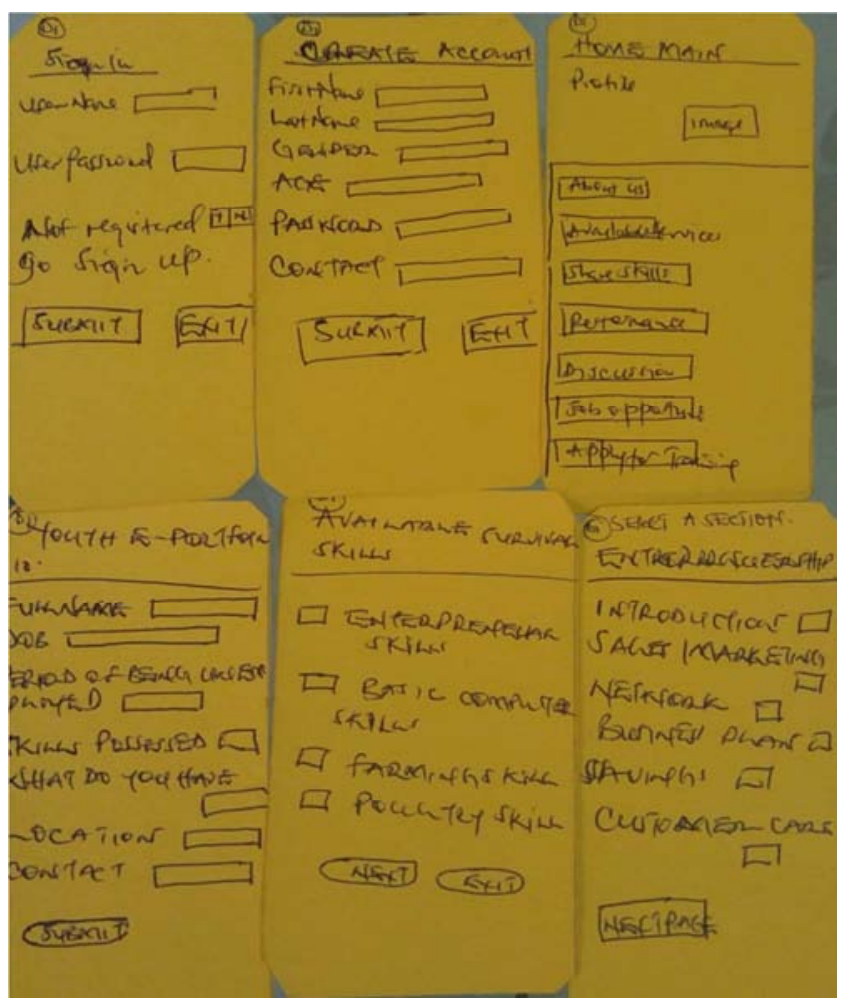

(a)

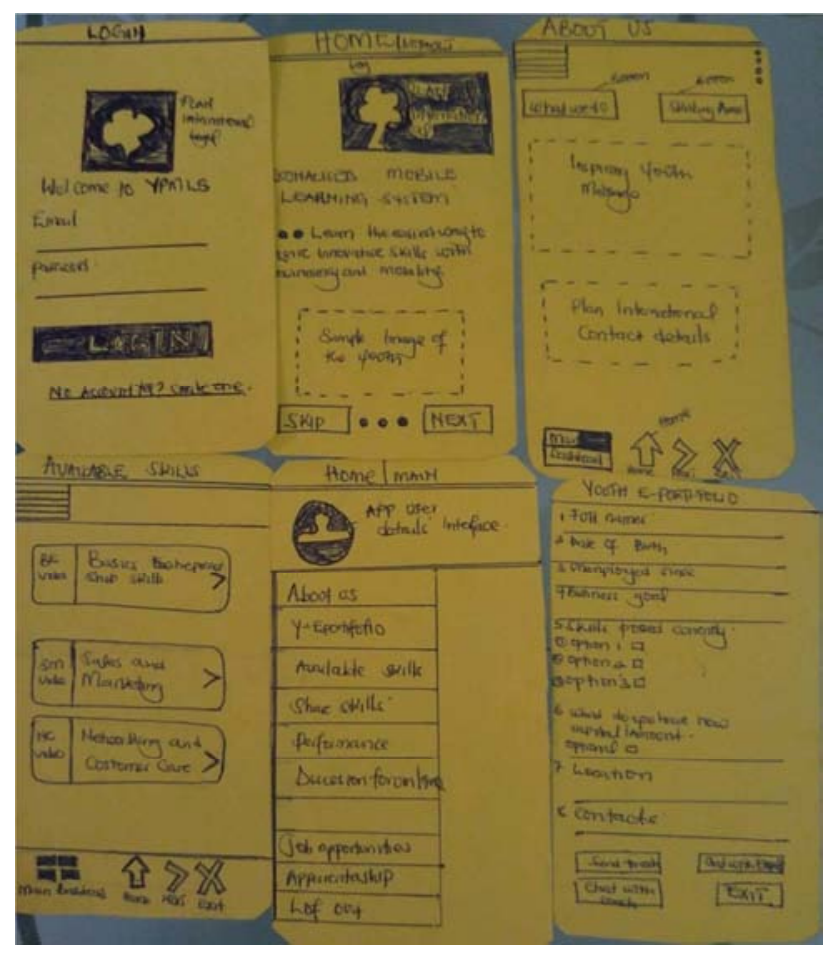

(b)

Figure 1. Sample paper prototypes: (a) Low-fidelity card prototype designs, (b) Final refined prototypes.

\subsection{PMLST Architecture}

As stated, the system can be accessed through a native mobile application and web based interface both querying apache web server while storing sustainable learning resources (Informal learning resources) in MySQL database. However, the infrastructure also accommodates workspace (external cloud services) formal learning resources from the cloud. The system presents learning resources through a remote data base connection mechanism on a mobile platform interface. This means resource access is defined by three access levels including; the interactive level (Skills or Course Authoring interface), Manipulative level (Resource catalogue management), and the data storage level (learning resource catalogue).

The interactive level consists of elements such as, video lecture element, Comment thread, assessment element, and the youth project management element. Data manipulation and the web scripting logics querying the back end skills management database were defined on the manipulative level. Multimedia filter objects, web intelligent, data analytics logics, SMS gateway integration logic generators were also defined on this layer.

Similarly, the learning resource database holding learning materials for the youth was also defined on the data storage level. Lastly, informal learning resources including; multimedia learning video, Audio, text documents and external formal learning resources from workspace were accommodated on this layer. 


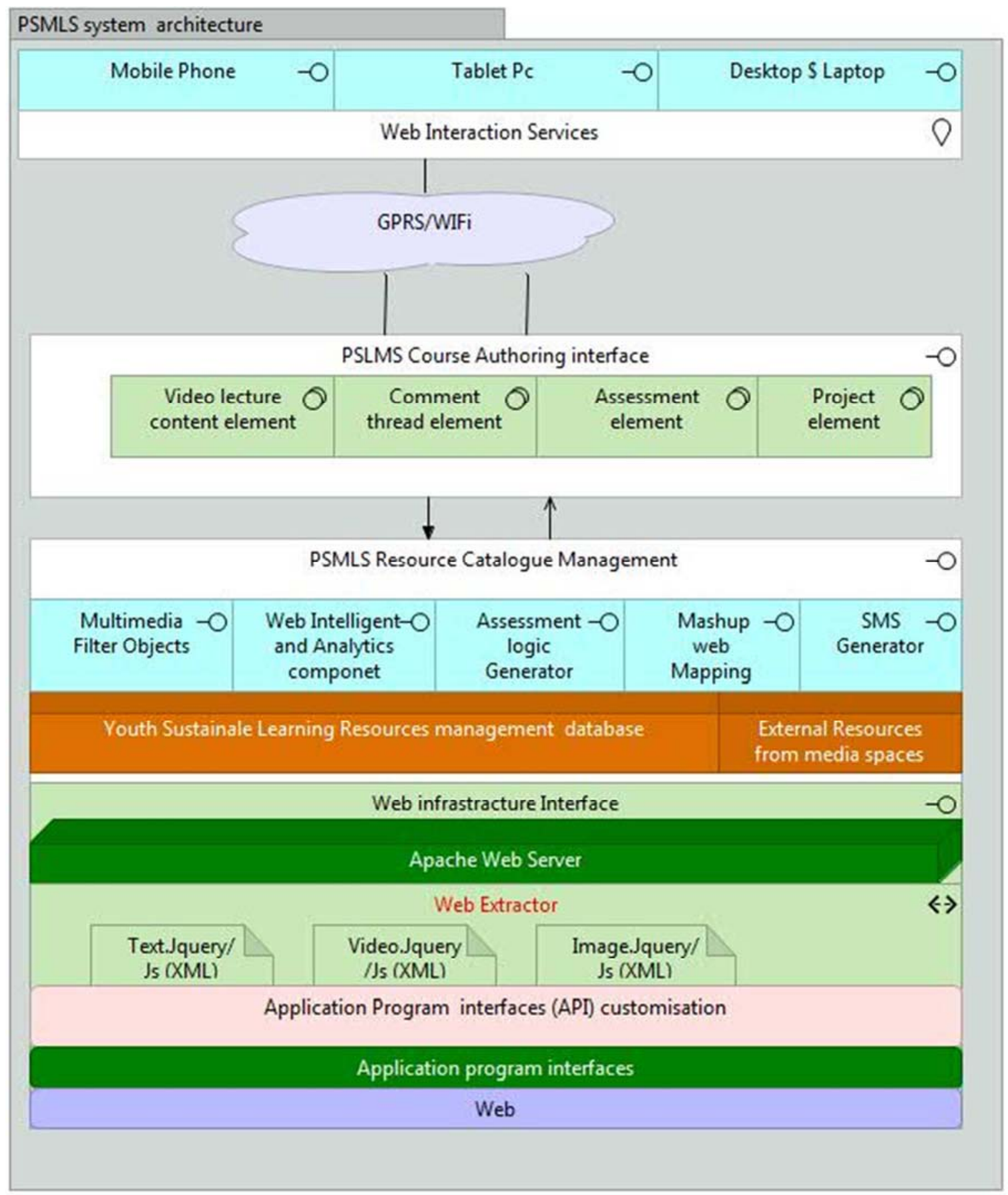

Figure 2. PMLST infrastructure.

\subsection{Major System Interactive Elements}

PSMS infrastructure consists of four major elements namely; the video lecture element, Comment thread, assessment element and the project management element.

\subsubsection{The Video Lecture Element}

This element allows systems users to view learning resources, discuss with trainers and other youth within or across the learning resource video. All this magic was achieved by the interactive video file element which is defined by four major action triggers; (1) list of embedded objects, (2) list of scene objects, (3) a link to comment thread and (4) a list of action triggers to make all the action happen. Scripting and event triggers were implemented by java script and XML programming languages.

\subsubsection{The Comment Thread}

The comment thread is basically responsible for holding user comments (feedbacks) at different scene modes within training videos. This is enhanced by a collaborative writing chat component that captures end users feedbacks in terms of comments. 


\subsubsection{The Assessment Element}

This was implemented to track student's skills masterly level. Here, self-assessment quiz act as core youth performance indicators to assess their understanding of subject matters. On the other hand, a video session time stamp user behavioural analytic element helps the youth coach to measure the youth and the learning resource engagement levels through a visual graph display feature.

\subsubsection{Youth Project Management Element}

It was strictly implemented to monitor youth business start-up intelligence through a self-determined business startup scenario project of choice. An intelligent form based business plan component is in place to capture the youth strategic business plan, and here one can be helped by the youth coach or skilled expert on what will work out better or not based on one's business plan.

There after a youth is prompted to submit a business deployment plan which is scheduled to be run for four weeks (A month). At the end of the day the youth coach is in position to capture the youth project performance of the active project via a basic project performance form as partial system monitoring mechanism option to the current field visit monitoring approach used by project managers.

\subsection{System Overview}

The youth can interact with the system either using a web based interface or a mobile tool (App). From here a youth participates in a needs assessment with the youth coach or skilled expert to evaluate the youth intended business goals (business cost benefit analysis). Thereafter, a youth provides his past experience in details using the E-portfolio component to access required business skills. From here the system bases on the provided e-portfolio details to respond on youth queries. Briefly the system helps the youth to select appropriate learning experiences or resources based on one's previous experience.

Users are also being given the opportunity to select a particular skill (section) within a fully packaged video learning curriculum using the in-built video navigation table of content controls. All this is enhanced by the back end learning intelligent algorithm. Meanwhile the learning environment gives the youths opportunity to select their learning path during the learning process. In addition, the system uses the collaborating writing and chat component to gather youth feedbacks during and after the learning process.

Self-assessment embedded quiz questions are used to test the youth skills masterly level of the course content. However, the youth coach uses the video sessions time stamp analytics graph display interface to track student to learning resources engagement levels.

After an entrepreneurship skills course, the youths are asked to take a project of interest using the system project interface. The project of interest can be selected from any formal or informal business startup area of interest. This is enforced to measure the youth business startup knowledge gathered while using our entrepreneurship curriculum provided at beginning. Strategically, the project component consists of a business plan capture interface, deployment plan element, and the deployed project monitoring interface used by the youth to present their project status to the trainers.

Other key features of the system entails; the contribute skills interface used by the youth to share his/her competencies with other youth using the video, the youth coach and skilled expert modules. Lastly, the system also accommodates the SMS component which is specifically used by the youth coaches to send instant messages to the youth on any upcoming training program or initiative.

\subsection{System Implementation Tools}

Design and development of the system interfaces was achieved using HTML5, XML and java programming languages. Scripting was enhanced by PHP, JQuery, and Json. Similarly, data manipulation was perfected with MySQL data manipulation language to enhance insertion, selection, and deletion of learning resources. The native mobile learning tool was implemented using Cordova mobile application development framework. However, Xamp server was used as the underlining local server to streamline services of a fully deployed web server. Briefly, the system is configured to query apache web server while storing sustainable learning resources (Informal learning resources) in MySQL database. The Mobile tool (App) displays learning resources to end users with a remote data base connection mechanism. Figure 3 below shows sample working PMLS tool working interfaces.

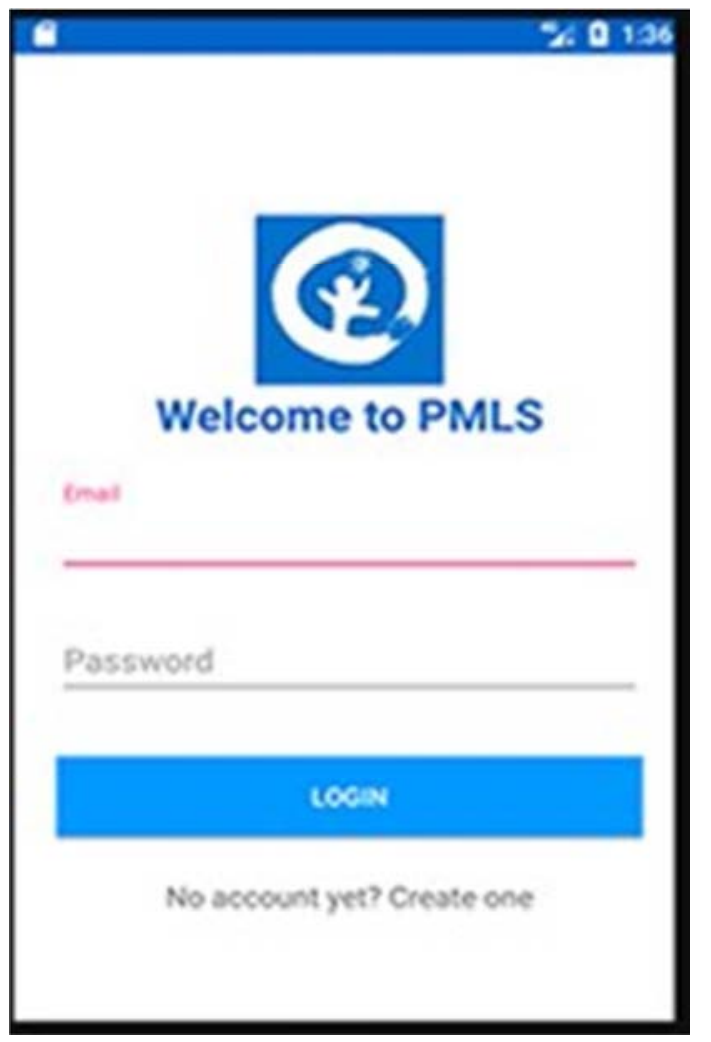



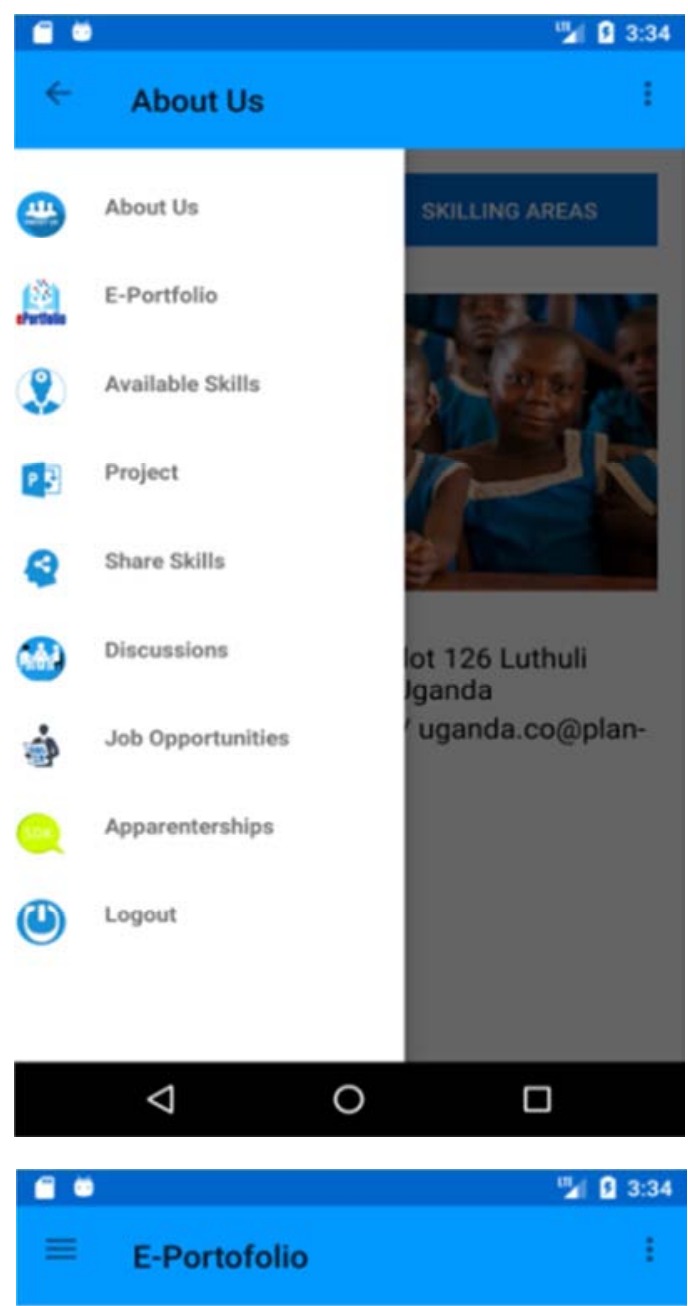

\section{Provide E-portofolio Details}

Email

lulefaridah@gmail.com

Date of Birth

Unemployed Since

Business Goa

What you posses Currently (Uganda Shillings)
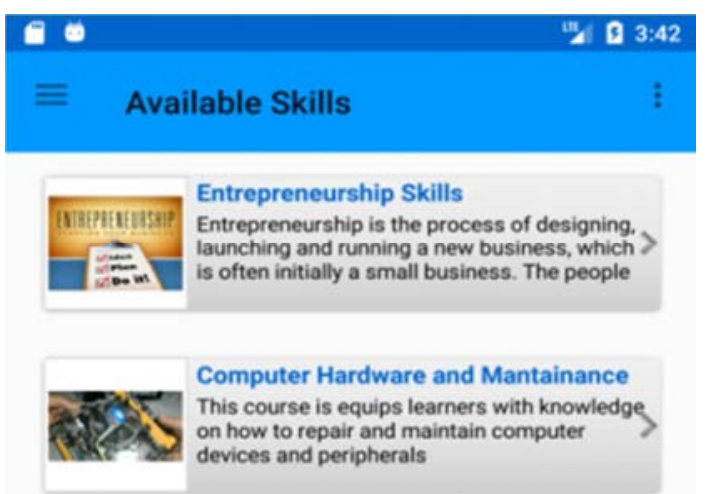

$\triangleleft \quad \circ \quad \square$

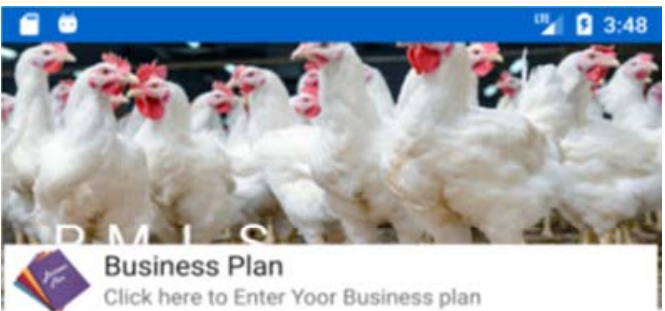

$\rightarrow$ Deployment Plan

Click here to Enter your deployment plan

Monitoring Performance

Click here to check your performance

(1) Quit

Click this card to Exit 


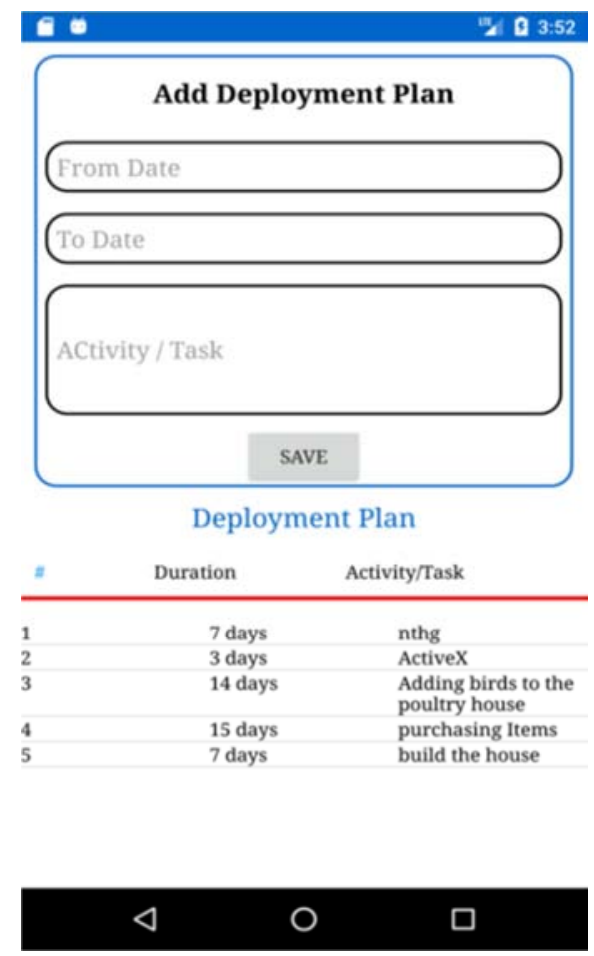

Figure 3. Sample PMLS tool interfaces.

\subsection{System Testing}

Unit testing was done throughout the system development phases to address system design errors and efficiency. Thereafter, the researcher involved himself into two initial phases of system testing. The first phase begun with testing the web-based component online, using a windows 8.0 operating system computer that was using an airtel $3 \mathrm{G}$ modem internet access. This was done three times with intention to test the web platform uptime and downtime responses. The process worked smoothly and the web based interface of the system was completely working fine.

The second phase involved testing the mobile app on mobile devices. This attempt was demonstrated on four mobile phones (Techno with 256MB of RAM, Samsung with 3GB RAM, fero and Nokia with 4GB RAM) and the PMLS tool application superbly worked well on three devices that were using $3 \mathrm{G}$ cellular network. However, on a Fero mobile phone with a smaller screen the content was not properly visible. In fact this stage helped the researcher to identify errors and bugs in the program codes.

\section{The Limitations of PMLS tool}

i. Due to the fact that the PML System tool has to be installed on a mobile device, it superbly works better on smartphones rather than basic phones. In simple terms, youth groups with basic phones have no opportunity to benefit from the services of the system. However, this is negligible considering the amount of mobile phone owners particularly the youth.

ii. Small sized screen phones have a constraint of visual content display; therefore course content might not be visually seen properly on small sized screen phones.

iii. Phones are not reliable to play high volumes of video files. However, study learning resources can be chunked to smaller sized video files of at least $8 \mathrm{mbs}$ which can easily run and utilize available phone memory.

iv. Not all disadvantaged youth are literate, but illiterate youth can get assistance from others in community or family members who are literate. In addition, we are looking forward to localize learning resources to address the challenge of illiteracy.

Despite of the mentioned limitations, the authors still found that mobile phones are very useful in dissemination of youth self-employment business startup knowledge (Skills).

\section{Results and Discussion}

Using a formative evaluation user response data gathering technique, 20 youth and 3 youth coaches' responses on the designed prototype was gathered using survey questionnaires.

Although all the 20 youth proven to be having mobile phones, but only 9 possessed smartphones and 10 youth at least had a two years' experience of interacting with mobile applications. However, none of the youth had a good background experience of using a mobile phone for learning purpose or even worked on any E-learning platform. Table below shows evaluators bio demographics;

Table 1. PMLS tool prototype evaluator's bio demographics $(N=20)$.

\begin{tabular}{llll}
\hline Character & & Frequency & Percentage \\
\hline \multirow{2}{*}{ Gender } & Male & 9 & 45.0 \\
& Female & 11 & 55.0 \\
\multirow{2}{*}{ Age } & $16-20$ & 7 & 35.0 \\
& $21-26$ & 11 & 55.0 \\
\hline
\end{tabular}

Table 2. Users Perception on PSMLS tool Usefulness.

\begin{tabular}{|c|c|c|c|c|}
\hline Performance expectancy & Strongly Agree & Agree & Disagree & Strongly disagree \\
\hline 1. I find the system useful in my daily life & $75 \%$ & $25 \%$ & & \\
\hline 2. PSMLS helps me master entrepreneurship skills more quickly & $60 \%$ & $20 \%$ & $10 \%$ & $10 \%$ \\
\hline 3. System helps me improve my Entrepreneurship skills & $85 \%$ & & $15 \%$ & \\
\hline 4. System would increase my business startup ideas and be more productive & $80 \%$ & & $20 \%$ & \\
\hline
\end{tabular}

Evaluation sessions started with the assessment of the youth attitudes on performance expectancy or perceived usefulness of the PML system as the youth survival entrepreneurship skill development tool (see table 2).
Findings revealed that $75 \%$ (15) of the respondents strongly agreed PML system tool is highly useful in their daily life, while $25 \%$ (5) of the respondents certainly agreed that the system can transform their everyday life through 
self-employment as a solution to a long term job seeking situation. It was then discovered that both impacted and nonimpacted youth economic empowerment program respondents believed that the PML system tool can empower them with self-employment business startup entrepreneurship skills at a cheapest cost if seriously given a consideration. Following the previous statement, 60\% (12) of respondents strongly agreed that using PMLS tool helps them to master business startup ideas quickly and more efficiently compared to the traditional training approaches. In fact one participant was quoted saying "Using PML system tool enables me access business startup idea from Plan international Uganda 24/7 without any need for physical field visits".

This was followed by $20 \%$ (4) agree responses. On the other hand $10 \%$ (2) respondents disagreed and $10 \%$ (2) strongly disagreed with others that, when it comes to real hands on skills development nothing can out compete the traditional classroom training approaches.

However, it was discovered that disagreement of 4 respondents was generally aligned on personality beliefs of the youth towards E-learning technologies as means to replace the traditional training approaches.

In regards to system's ability to improve youth entrepreneurship competencies, $85 \%$ (17) subjects strongly agreed that the system improves their business startup knowledge and 4 respondents argued that a community of practice system mechanism which brings on board youth coach, skilled expert and the youth makes life more easily compared to the traditional timely scheduled training programs. While $15 \%$ (3) disagree with the 17 subjects stating that they prefer a traditional training approach. But it was discovered all the disagreement responses were gathered from non-impacted-youth economic empowerment program youth. When it came to system's ability to encourage youth to become job creator and be more productive $80 \%$ (16) strongly agreed and quoted saying "True but the more challenging factor is the startup capital" but this is an awesome tool. However, 20\% (4) disagreed from other 16 subjects stating that the government and other private institution cannot accept dissemination of this kind of crucial open education materials free of charge.

This was quite an interesting feedback, however it was later discovered that the respondents were unaware of Uganda ICT or Open education resource strategy which also supports open education for sustainable development. In other words, this finding revealed that empowering unemployed out of school youth with survival entrepreneurship skills can aid or alleviated youth unemployment challenges in developing countries like Uganda if the youth are being encouraged to become job creators on the continent at large.

\subsection{Users Perception on PMLS Tool Ease of Use}

Table 3. Users Perception on PMLS tool Ease of Use.

\begin{tabular}{llll}
\hline Effort expectancy & Strongly Agree & Agree & Disagree \\
\hline 1. The system is easy to use & & $75 \%$ & $25 \%$ \\
2. System fastens the process of skills development & $100 \%$ & & \\
3. I finding the system flexible to interact with & $85 \%$ & $15 \%$ & $10 \%$ \\
4. Learning to use the system is easy for me & $90 \%$ & $80 \%$ & $20 \%$ \\
5. User interfaces easily visible and easy to work on & & & \\
\hline
\end{tabular}

In regards to youth perception on system ease of use, $75 \%$ (15) of youth respondents argued that PMLS tool interfaces are easy to work on and can be used by other youth with low computer skills for the first time. And 25\% (5) indicated that squeezing of many required attributes desired from them most especially from the Business plan interface makes use of the system confusing hence suggested if possible to stick with horizontal or hierarchical arrangement of attributes on all interfaces.

Out of 20 subjects responses $100 \%$ (20) of respondents strongly agree that our PMLS tool for sure speeds up the process of survival skills development because it is a 5 step process required from the survival skills seeker to master skills in depth. On the other hand, $85 \%$ of (17) subject respondents stated that the system is flexible to interact with and does not require much skills to be operated due to clearly structured navigation sequential designs. However, 15\% (3) of the rest disagreed with the previous statement, arguing that one might need a $24 / 7$ support to use the system. This signified that there is much need for initial user training on how the PML system tool works before it is released.

Youth perception on learning how to use PMLS tool indicated that $90 \%$ (18) of responses strongly agreed that learning how to operate PMLS tool is not a big deal, however they recommended first training at least before they are given the opportunity to manage the rest of the entire learning process. On the other hand $10 \%$ (2) disagreed with the statement. Youth feedback on how easily visible and easy to work on the system interfaces was also recorded. Where majority of the youth participants argued that it is easier to work on the system interfaces due to classical alignment, and flow of the navigation menus which are easily visible by $80 \%$ (16) response rate. And only $20 \%$ (4) disagreed with the rest reason being, poorly selected contradicting color themes applied within the system interface designs. This was critically noted and given a serious consideration by the researcher. Findings from here implied that careful colour selection on user interfaces needs to be given a consideration.

\subsection{Youth Perceptions on the PSMLS Facilitating Condition}

Regarding possession of handheld devices required to use the system, such as Mobile phones, tablets, computer 
resources, $85 \%$ (17) of participants agreed that they do possess some of these resources required to access the system. However $15 \%$ (3) proved not to own any of the resources required to access the system but argued they have colleagues who can lender to them devices such as smartphones and tablets to access the system. Of $85 \%$ (17) candidates assumed to possess mobile phones, $52.9 \%$ (9) clearly indicated that they possess a smartphone, leaving $47 \%$ (8) being with basic button phones. But computer resource owner were not recorded anywhere.

Majority of respondents argued that they possess knowledge required to use the system by a percentage rate of 70 (14), and only $30 \%$ (6) disagreed. It was clearly pointed out by the researcher that the language bias (English) dominated the disagreement by this particular group and 2 of the respondents suggested that if the training materials can be localized in the language they can understand better, it will maximize the process of skills development. In relation to availability of help in case someone encounters a challenge while using the system, $60 \%$ (12) agreed that they have volunteers who can give them assistance in case they have encountered a challenge while working on the system. In other words after careful focus group discussions, it was observed that majority of the youth were counting on the youth coach because they are community based. However, 30\% (6) disagreed with an argument, by stating that "we have specific people who can help us in case of inconvenience but hard to get". Similarly, $10 \%$ (2) strongly disagreed that we do not have any kind of person who can give us assistance in case we have encountered a challenge while using the system.

In relation to the ICT infrastructure, youth respondents argued that plan international ICT infrastructure possess what it takes to support the services of the PML system tool environment with a $100 \%$ response rate. In addition to that, majority of the youth agreed with $80 \%$ (16) response rate with suggestion that Uganda economy ICT infrastructure can support services of the system based on the current growth in Cellular networks coverage. And 2 respondents were quoted saying "Deployment of fiber cables country wide presents interesting potentials to support the proposed system services. Table 4 below show youth responses on the facilitating condition towards PSML system adoption.

Table 4. Youth Perceptions on the PSMLS facilitating Condition.

\begin{tabular}{|c|c|c|c|c|}
\hline Facilitating Condition & Strongly Agree & Agree & Disagree & Strongly Disagree \\
\hline 1. I have devices required to access the system & & $85 \%$ & $15 \%$ & \\
\hline 2. I have the knowledge required to use the system & & $70 \%$ & $30 \%$ & \\
\hline $\begin{array}{l}\text { 3. I have a specific person who can give me assistance in case } i \text { have encounter a } \\
\text { challenge while using the system }\end{array}$ & $60 \%$ & & $30 \%$ & $10 \%$ \\
\hline 4. Plan international infrastructure can support the mobile learning system & & $100 \%$ & & \\
\hline 5. Our country ICT infrastructure can support the mobile learning system infrastructure & & $80 \%$ & $20 \%$ & \\
\hline
\end{tabular}

Study findings from the above presented data on youth perception toward the PML system tool facilitating condition showed that the youth in developing countries like Uganda currently possess mobile devices that can support mobile learning programs for sustainable development. In addition, findings also revealed that there's slight change in terms of ICT infrastructure development in developing countries like Uganda's economy. However, development of our PML system tool was streamlined on the recent developments in mobile technologies in developing countries.

\subsection{Youth Perception Toward the Social Influence Impact}

$65 \%$ (13) participants stated that their youth peers argued that the system is more crucial in any youth everyday life because it encourages one to acquire self-reliance business startup skills and promised to recommend PSML system tool to their colleagues the day it will be unveiled officially.

On the other hand, 35\% (7) subjects stated that their youth counter parts silently through whispers told them that the system cannot help them acquire business startup ideas.

Meanwhile, $100 \%$ (20) responses were gathered from youth coaches and skilled expert's stating that they will often recommend the system to disadvantaged out of school unemployed youth.

Briefly, study findings revealed that the social influence factor plays a critical role in youth technology adoption in developing countries like Uganda. In fact this argument correlates with Graf findings, which also clarified that the social influence factor of human being plays an influential role in technology adoption [45]. Table 5 below shows youth responses on the influence of social factor in use and adoption of the PSML system.

Table 5. Youth Perception toward the Social influence impact.

\begin{tabular}{|c|c|c|c|c|}
\hline Social Influence & Strongly Agree & Agree & Disagree & Strongly Disagree \\
\hline $\begin{array}{l}\text { 1. Most of my youth peers thinks that the App is awesome to give a try } \\
\text { 2. Youth coach, project manager, and skilled experts argues me to use the system }\end{array}$ & & $\begin{array}{l}65 \% \\
100 \%\end{array}$ & $35 \%$ & \\
\hline
\end{tabular}

\subsection{Influence of Voluntariness}

Voluntariness of use variable was not investigated because of the following reason; Voluntariness of use technology predictive variable was not under study because lifelong learning for sustainable development most especially for the youth is highly voluntary (Burns and Lewis, 2015). So there was no need to study the impact predictive variable within our study. 


\subsection{Youth Coaches Responses on the Developed PSMLS Prototype}

Although the primary system users were the youth, but there was also need to gather other stakeholder's feedback on the designed system prototype. Below were gathered responses from three youth coaches. All the three youth coach subjects stated that the system is useful to the youth, and argued the youth to frequently use the system after official unveiling. In regards to the system ease of use, two youth coach argued that the system is easy to use but recommended localization of the learning content such that several illiterate youth groups can benefit from the services of the PMLS tool. However, one youth coach disagreed with the others arguing giving the youth opportunity to be in charge of their learning process will encourage laziness. But this was a disagreement with the other two youth coaches.

Henry Kironde one of the youth coach in Kamuli district stated that giving the youth opportunity to be in charge of their learning process through a personalized learning environment will encourage creativity and innovativeness among the youth rather than being spoon-fed throughout the learning process. In addition to that, all the three youth trainers (Coaches) reported that plan international ICT infrastructure is stable enough to support implementation of a PMLS tool infrastructure. In addition, two were quoted saying "This mission will be achieved due to increased penetration of mobile devices by the youth" in Uganda's economy. Lastly all the three youth coaches suggested that this learning environment should be used as a blended learning approach to work in conjunction with the currently traditional face to face skills training approach.

\section{Conclusion}

This research study was conducted in a research domain lifelong mobile learning for youth skills development (LmL4SD) a new research area within ICT for youth workforce development (ICT4WD), focusing specifically at empowering youth with sustainable employability skills access using mobile technologies. In fact this research idea was streamlined on the current increase in youth mobile penetration in developing countries like Uganda. Although literature presents promising E-learning initiatives for youth employability skills development, but success to these initiatives has been held back by pedagogical usability and accessibility barriers in developing countries.

To address the above mentioned barriers, this study proposed a youth entrepreneurship skills E-learning system ported on mobile technology with an integrated informal lifelong learning model, and a mobile tool that supports access and usability concerns of out-of-school youth lifelong learners in Uganda's economy as a case study. A personalised mobile learning system with both web and native mobile application was implemented as the end product but specifically designed based on a user centred participatory design approach.
Study findings revealed that a personalised mobile learning system streamlined on an integrated informal out of school youth lifelong learning model, designed based on a user centered participatory design approach bridges pedagogical usability and accessibility concerns in E-learning systems implementation for youth sustainable skills in Uganda's economy. However, the same approach is applicable and can be adopted in other developing countries.

In addition, findings also revealed that all UTAUT technology adoption variables play a key critical role in the success and adoption process of youth sustainable e-learning programs in developing countries. Similarly, staff perceptions on the developed prototype were also positive in regards to the system's ability to reach the unreached youth, and the ability of the system to monitor youth active or ongoing projects.

\section{Recommendations}

i. There is still need for further exploration of ICT blended learning opportunities for youth sustainable skills development in developing countries like Uganda.

ii. More research is still needed to fully test the impact of a self-determined pedagogical learning approach in the design and development of lifelong learning environments for sustainable development.

iii. While designing community based virtual learning environment for out of school lifelong learners in developing countries, targeted learning environment users should be given opportunity to take part in the design and development stages of their own learning technologies.

iv. More emphasis is still needed to strengthen, and design policies governing open education resources for lifelong learners in Uganda's economy.

v. More investment inform of funds are still needed to support youth economic empowerment programs for instance start-up capital.

\section{Direction for Future Work}

We are currently working on integration of both the comment thread of the PML system such that it can be displayed within the video lecture interface on both web and mobile interfaces. Not as it is currently displayed externally outside the video content interface.

In addition, our PML system can further be extended to accommodate a simulation learning component that can be used by the youths to organize their discoveries in terms of findings during and after the learning process (mind mapping component). Lastly, since we had field study evaluation challenges as a contextual study limitation, another research study can be done to determine the impact of mobile technologies on youth workforce skills development using a larger sample size. 


\section{Acknowledgements}

I want to acknowledge the extraordinary assistance of aspiring Doctor Andrew Lukyamuzi my supervisor who accepted to bear my endless phone calls, visits and emails even at awkward hours in the course of developing this project. I greatly say thank you. Similarly, I thank my farther (Mr. Mubarak Mugerwa) and my Mother (Alice Namukkwaya) and dear brothers (Kabanda Henry; Mubarak) for their support during the course of this project.

In addition, I wish to thank Plan international Uganda most especially the youth economic empowerment unit for their support and having accepted my request to carry out my project with them. Meanwhile, any opinions expressed in this paper are those of the authors alone.

\section{References}

[1] Popkin, S. J., Scott, M. M. and Galvez, M. (2016) Teens and Food Insecurity in America.

[2] World Economic Forum (2017) The Future of Jobs and Skills in Africa Preparing the Region for the.

[3] Imaka, I. (2017) 'Govt's new Shs890b plan to curb youth unemployment - Daily Monitor'. Available at: http://www.monitor.co.ug/News/National/Govt--Shs890bplan--youth--unemployment/688334-3873586r4lsmoz/index.html[Accessed on 15 July 2017].

[4] Hailu, G. K. (2015) Anti-Human Trafficking Measures in Tigray, Ethiopia: A Human Rights-Based Perspective.

[5] Onuoha, F. C. (2014) SPeCIAL RePoRt 2301, New York. doi: $10.1080 / 13688800903395585$.

[6] Kaweesa, G. (2017) 'Embrace Volunteerism To Tackle Youth Unemployment'. Available at: https://www.newvision.co.ug/new_vision/news/1466988/embr ace-volunteerism-tackle-youth-unemployment[Accessed 12 june 2017].

[7] Namuggala, V. F. (2017) 'Gambling, Dancing, Sex Work: Notions of Youth Employment in Uganda.' IDS Bulletin. doi: 10.19088/1968-2017.127.

[8] International, P. child (2015) 'Youth Unemployment Causes and Solutions - Peace Child International'.

[9] MasterCard Foundation (2017) Invisible Lives: Understanding Youth Livelihoods In.

[10] Ministry of Finance, P. and E. D. (2014) Uganda's Employment challenge.

[11] International Alert and UPFYA (2013) Youth participation in government Programmes in Uganda | International Alert. Available at: http://www.internationalalert.org/resources/publications/youth-participationgovernment-programmes-uganda[Accesses 11 june 2017].

[12] Children, S. the (2016) 'Youth Employment Programs In The Philippines'. Available at: https://resourcecentre.savethechildren.net/node/12111/pdf/you th_employment_programs_in_the_philippines.pdf [Accessed 1 January 2017].
[13] Pletscher, M. (2015) Youth unemployment in Uganda: Roots of the problem and possible ways to mitigate them. Available at: http://fontes.no/foundation/wpcontent/uploads/2015/06/Michael-Pletscher_Youthunemployment-in-Uganda.pdf [Accessed 15 may 2017].

[14] Aguma, D. (2017) THE 3 rd LEAP CONFERENCE Full Report Author: Dennis Aguma.

[15] Mohd, R. W. and (2015) '1726-1731.pdf'.

[16] Anderson, D., Chen, F. and Schroeder, K. (2010) Innovation and Technology for Youth Employment.

[17] United Nations Educational, S. and C. O. (UNESCO (2017) Using ICTs and Blended Learning in Transforming TVET.

[18] India National skills report (2016), Skilling India Transforming India.

[19] UNESCO (2016) 'Conceptions and realities of lifelong learning', pp. 1-24. Available at: http://unesdoc.unesco.org/images/0024/002456/245626e.pdf [Accessed 23 July 2017].

[20] Ogunleye, A., Owolabi, T. and Adeyemo, S. (2013a) 'The Design and Development of a Web-Based E-learning Platform for the Understanding and Acquisition of Various Entrepreneurial Skills in SMEs and Industry', 3 (4), pp. 239251.

[21] MInistry of Education, A. and C. (2015) State Of Education, Arts And Culture Address.

[22] Francis, O. et al. (2013) 'E-Skill Information Acquisition Software: A Key to Poverty Alleviation Or Self Reliance', 6(1), pp. 1-14.

[23] Nygren, M. (2016) 'Developing a Mobile Learning Application for Entrepreneurship Education in Uganda and Zambia Developing a Mobile Learning Application for Entrepreneurship Education in Uganda and Zambia Examensarbete utfört i Medieteknik Marcus Nygren'.

[24] Https://jump.co.zm/ (2018) JUMP Entrepreneurship and startup resources. Available at: https://jump.co.zm/ [Accessed 24 December 2017].

[25] Esterhuyse, M. and Scholtz, B. (2015) 'Barriers to e-Learning in a Developing Country: An Explorative Study’, pp. 354-367.

[26] Almarabeh, T. et al. (2014) 'the University of Jordan ELearning Platform: State, Students' Acceptance and Challenges', (November), pp. 999-1007.

[27] Kasse, J. P. and Balunywa, W. (2013) 'an assessment of elearning utilization by a section of Ugandan universities: challenges, success factors and way forward', pp. 4-8.

[28] Boticario, J. G. and Santos, O. C. (2005) 'Issues in Developing Adaptive Learning Management Systems for Higher Education Institutions'.

[29] Tarus, J. K. (2015) Tarus. Available at: http://www.irrodl.org/index.php/irrodl/article/view/1816/3196 [Access 17 September 2016].

[30] Magoulas, K. K. and G. D. (2017) 'An Architecture for Smart Lifelong Learning Design An Architecture for Smart Lifelong Learning Design', (September), p. 7. doi: 10.1007/978-98110-2419-1. 
[31] GSMA (2015) the Mobile Economy Sub-Saharan Africa 2015, GSM Association. doi: 10.1007/s10461-016-1458-y.

[32] Christina Blumel (2014) Trends in icts for youth workforce. Available https://www.fhi360.org/sites/default/files/media/documents/Te chLab_TrendsInICTs_v8-508.pdf [Accessed 16 march 2017].

[33] Ogunbase, A. O. (2016) Pedagogical Design and Pedagogical Usability of Web- Based Learning Environments: Comparative Cultural Implications from Africa and Europe.

[34] Fox, D. F. and L. (2014) Youth unemployment in sub-sahara Africa. Available at: https://openknowledge.worldbank.org/bitstream/handle/10986 /16608/9781464801075.pdf [Accessed 14 march 2017].

[35] Bulger, M. (2016) Personalized Learning: The Conversations We're Not Having.

[36] Bartle, E. (2015) Personalised learning: an overview A discussion paper prepared for.

[37] Hammond, J. A., Cherrett, T. J. and Waterson, B. J. (2013) 'the Usability and Effectiveness of Interactive Video as a Complementary Child Pedestrian Training Activity', 3 (5). doi: 10.7763/IJEEEE.2013.V3.261.

[38] Zelezny-green, B. R. (2017) Lifelong mobile learning for skills development in low- and middle-income contexts. Available at: file://C:/Users/med/Downloads/Lifelong mobile learning fo r_skills_development-RondaZelezny-Green(3).pdf $\quad$ [accssed 12 July 2017$]$.

[39] Luna, C. (2015) 'Education Research and Foresight What Kind of Learning', pp. 1-14. Available at: http://www.worldbank.org/en/news/feature/2015/08/04/empo wering-ugandas-youth-to-be-job-creators [Accessed 11 june 2017].

[40] Halsall, J. P., Powell, J. L. and Snowden, M. (2016) 'Determined learning approach: Implications of heutagogy society based learning', Cogent Social Sciences. Cogent, 37, pp. 1-11. doi: 10.1080/23311886.2016.1223904.

[41] Narayan, V. and Herrington, J. (2012) 'Towards a theoretical mobile heutagogy framework', pp. 1-11.

[42] Fischer, G. (2015) 'Beyond hype and underestimation: identifying research challenges for the future of MOOCs Gerhard Fischer Department of Computer Science, and Institute of Cognitive Science', (July 2014), pp. 2-7. doi: 10.1080/01587919.2014.920752.

[43] UNESCO (2016) 'Conceptions and realities of lifelong learning', pp. 1-24. Available at: http://unesdoc.unesco.org/images/0024/002456/245626e.pdf [Accessed 23 July 2017].

[44] Miguel Baptista Nunes and Guo Chao Peng (2011) 'Universities of Leeds, Sheffield and York', pp. 3-12.

[45] (Hafedh Said Abdullah, 2017) Hafedh Said Abdullah, A. R., 2017. FulltextThesis(1).pdf . [online]. Available at: $<$ https://bura.brunel.ac.uk/bitstream/2438/14514/1/FulltextThe sis.pdf $\% 20>$ [Accessed 12 Dec. 1018].
[46] Graf-Vlachy, L. and Buhtz, K. (2017) 'Social Influence in Technology Adoption Research: a Literature Review and Research Agenda', Proceedings of the 25th European Conference on Information Systems (ECIS), 2017, pp. 23312351.

[47] UNFPA (2017) Population and development:World Population Day 2017 "Strengthen Youth Competitiveness for Sustainable Development".

[48] Center on Innovations in Learning, C.., 2016. ED568173.pdf. [online] Philadelphia, Available at: $<$ https://files.eric.ed.gov/fulltext/ED568173.pdf>

[49] Holmes, W. et al. (2018) Technology-enhanced Personalised Learning Untangling the Evidence.

[50] Nandigam, D. (2014) 'Personalized Learning: Current Status and Potential', (December), pp. 2-7. doi: 10.1109/IC3e.2014.7081251.

[51] Kats, Y. ed., 2013. Learning Management Systems and Instructional Design: Best Practices in Online Education. [online] IGI Global.

[52] Rauterberg, M. (2014) 'User Centered Design: What, Why, and When', (June), pp. 1-5.

[53] Blaschke, L., Hase, S. and Hase, S. (2015) 'Heutagogy: A holistic framework for creating 21 st century self-determined learners Chapter 2 Heutagogy: A Holistic Framework for Creating Twenty-First-Century Self-determined Learners', (November), pp. 8-18. doi: 10.1007/978-3-662-47724-3.

[54] Mcpherson, M. M. (2016) 'Assignment_5_Final_Paper_Heutagogy_and_Self_Determine d_Learners_in_an_Online_Master_of_Science_Program', pp. $1-47$.

[55] Muhibul Haq, 2015. A Comparative Analysis of Qualitative and Quantitative Research Methods and a Justification for Adopting Mixed Methods in Social Research.

[56] Burns, D. and Lewis, A. (2015) Valuing Volunteering. Available at: https://www.vsointernational.org/sites/default/files/the_role_of _volunteering_in_sustainable_development_2015_vso_ids.pdf

\section{Biography}

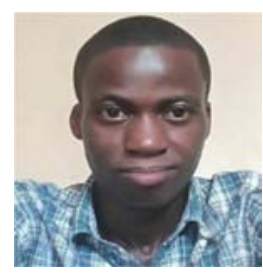

Tamale Med was born in 1991 and raised in Uganda East Africa. The primary academic concentrations of his studies were in information systems design and security. Tamale is a 2018, and 2014 graduate of Uganda martyrs University Nkozi in Kampala city with a Master's degree in information systems and Bachelor's degree in information Technology. He has worked extensively in areas of ICT technical support and architectural design within private and public sectors such as Opportunity Bank Uganda. Tamale's research interest aligns in areas of E-learning and Cyber security. 